\title{
Clinical risk factors for pre-eclampsia determined in early pregnancy: systematic review and meta-analysis of large cohort studies
}

\author{
Emily Bartsch, ${ }^{1}$ Karyn E Medcalf,, Alison L Park, ${ }^{2}$ Joel G Ray ${ }^{3}$ on behalf of the High Risk \\ of Pre-eclampsia Identification Group
}

'University of Toronto, Toronto,

Canada

2Institute for Clinical Evaluative

Sciences, Toronto, Canada

${ }^{3}$ Departments of Medicine,

Health Policy Management and

Evaluation, and Obstetrics and

Gynecology, St Michael's

Hospital, University of Toronto,

Toronto, Canada

Correspondence to:

J G Ray, Department of

Medicine, St Michael's Hospital,

30 Bond Street, Toronto,

Ontario, M5B 1W8, Canada

rayj@smh.ca

Additional material is published online only. To view please visit

the journal online.

Cite this as: BMJ 2016;353:11753 http://dx.doi.org/10.1136/bmj.i1753

Accepted: 15 March 2016

\section{ABSTRACT}

\section{OBJECTIVE}

To develop a practical evidence based list of clinical risk factors that can be assessed by a clinician at $\leq 16$ weeks' gestation to estimate a woman's risk of pre-eclampsia.

DESIGN

Systematic review and meta-analysis of cohort studies.

DATA SOURCES

PubMed and Embase databases, 2000-15.

\section{ELIGIBILITY CRITERIA FOR SELECTING STUDIES}

Cohort studies with $\geq 1000$ participants that evaluated the risk of pre-eclampsia in relation to a common and generally accepted clinical risk factor assessed at $\leq 16$ weeks' gestation.

\section{DATA EXTRACTION}

Two independent reviewers extracted data from included studies. A pooled event rate and pooled relative risk for pre-eclampsia were calculated for each of 14 risk factors.

RESULTS

There were 25356688 pregnancies among 92 studies. The pooled relative risk for each risk factor significantly exceeded 1.0, except for prior intrauterine growth restriction. Women with antiphospholipid antibody syndrome had the highest pooled rate of preeclampsia $(17.3 \%$, $95 \%$ confidence interval $6.8 \%$ to

\section{WHAT IS ALREADY KNOWN ON THIS TOPIC}

Clinical practice guidelines strongly recommend that physicians and midwives start treatment with aspirin at 12-16 weeks' gestation in a woman at high risk of pre-

eclampsia

These guidelines do not provide a systematic approach for identifying a woman at high risk by using readily available clinical risk factors known before 16 weeks' gestation

There is a need for a clear, concise, and evidence based list of risk factors that clinicians can use, before 16 weeks' gestation, to estimate a woman's risk of pre-eclampsia

\section{WHAT THIS STUDY ADDS}

This study analyzed large cohort studies to generate the absolute pooled risk of developing pre-eclampsia in the presence or absence of one of 14 common risk factors, the pooled relative risk of developing pre-eclampsia in the presence or absence of one of these risk factors, and the pooled population attributable fraction for pre-eclampsia in relation to each risk factor

Antiphospholipid antibody syndrome, prior pre-eclampsia, chronic hypertension, pregestational diabetes, assisted reproductive technology, and $\mathrm{BMI}>30$ were most strongly associated with a high rate of pre-eclampsia, suggesting that the presence of any one might suffice to designate a woman as "high risk"

$31.4 \%)$. Those with prior pre-eclampsia had the greatest pooled relative risk (8.4, 7.1 to 9.9). Chronic hypertension ranked second, both in terms of its pooled rate $(16.0 \%, 12.6 \%$ to $19.7 \%)$ and pooled relative risk (5.1, 4.0 to 6.5$)$ of pre-eclampsia. Pregestational diabetes (pooled rate $11.0 \%, 8.4 \%$ to 13.8\%; pooled relative risk 3.7, 3.1 to 4.3 ), prepregnancy body mass index $(\mathrm{BMI})>30(7.1 \%, 6.1 \%$ to $8.2 \% ; 2.8,2.6$ to 3.1 ), and use of assisted reproductive technology $(6.2 \%, 4.7 \%$ to $7.9 \% ; 1.8,1.6$ to 2.1) were other prominent risk factors.

\section{CONCLUSIONS}

There are several practical clinical risk factors that, either alone or in combination, might identify women in early pregnancy who are at "high risk" of preeclampsia. These data can inform the generation of a clinical prediction model for pre-eclampsia and the use of aspirin prophylaxis in pregnancy.

\section{Introduction}

Pre-eclampsia is a common condition of pregnancy, marked by the onset of hypertension and proteinuria. ${ }^{12}$ At least 75 randomized controlled trials have shown that antiplatelet agents- especially aspirin-effectively and safely prevent pre-eclampsia among women at moderate or high risk of developing the condition. ${ }^{3-5}$ Meta-analyses have shown a 53\% (95\% confidence interval $35 \%$ to $66 \%$ ) reduction in relative risk for pre-eclampsia when aspirin is started at 12-16 weeks' gestation among high risk women. ${ }^{6-8}$ Internationally published clinical practice guidelines strongly recommend that physicians and midwives use aspirin to treat women at high risk of pre-eclampsia..$^{9-11}$ These guidelines suggest choosing from a list of single risk factors to identify women at high risk or from a combination of moderate risk factors, but the derivation of this partial list was neither systematic nor based on clinical risk factors that are available up to 16 weeks' gestation. Focus on those at high risk of pre-eclampsia avoids the treatment of healthy women, who gain little or no benefit from aspirin prophylaxis. ${ }^{912-14}$

Many randomized controlled trials of aspirin prophylaxis did not describe the criteria they used to define a woman as high risk, and others used abnormal findings on uterine artery Doppler ultrasonography, which has limited sensitivity, is rarely done before 16 weeks, and has limited availability among midwives and family practitioners. ${ }^{15}$ Other studies have proposed several risk factors to characterize women at high risk of pre-eclampsia, including nulliparity, older age, chronic hypertension, and prepregnancy diabetes mellitus. ${ }^{1516}$ 
Yet again, the absolute and relative importance of one risk factor over another has not been systematically assessed.

Given the limitations and variability in the current criteria used to identify women at high risk of pre-eclampsia, there is a need for a clear, concise, and evidence based list of indicators to estimate a woman's risk. These indicators should consider events in any previous pregnancy as well as current pregnancy factors that can be efficiently gathered at an early prenatal visit. To generate this list, we completed a meta-analysis of large cohort studies of one or more risk factors for pre-eclampsia. To generate three practical estimates, we determined the absolute risk of developing pre-eclampsia in the presence versus absence of a given risk factor; the relative risk of developing pre-eclampsia in the presence versus absence of a given risk factor; and the population attributable fraction for pre-eclampsia in relation to each risk factor. The first two metrics are useful to clinicians, and the third metric can help guide public health policy at the population level. Finally, we outlined how our generated list of individual risk factors might be applied to identify "high risk" women, such as those who could benefit from aspirin prophylaxis.

\section{Methods}

\section{Search strategy}

We searched PubMed and Embase, restricting our query to publications in English with abstracts available from 2000 to June 2015. The search strategies are shown in appendix 1.

\section{Selection of studies}

We identified publications investigating the association between pre-eclampsia and at least one risk factor in a previous pregnancy or in the current pregnancy. We examined those risk factors described in the published guidelines and reviews ${ }^{13-19}$ that were patient specific, that were readily recalled by a woman or abstracted from her prior pregnancy record, and that a general clinician could ascertain in the first trimester of pregnancy. For these reasons, and the observation that a family history in risk assessment tends to have a low sensitivity (that is, low recall), ${ }^{20}$ we did not assess family history of pre-eclampsia as a risk factor. We also limited our selection to large sample cohort studies because they tend to be more representative of the general population than small single centre studies and they have sufficient statistical power to assess less prevalent, but potentially important, risk factors. ${ }^{21}$

Selected risk factors from a previous pregnancy included a history of pre-eclampsia, placental abruption, fetal intrauterine growth restriction, and stillbirth.

Current pregnancy risk factors included nulliparity, advanced maternal age, high body mass index (BMI), chronic hypertension, prepregnancy diabetes mellitus (type 1 or type 2), chronic kidney disease, systemic lupus erythematosus, antiphospholipid antibody syndrome, assisted reproduction, and multiple pregnancy.
The resulting papers were first screened by title and abstract. Full text articles were obtained if they met all of the following screening criteria: a cohort study design with a minimum sample size of 1000 pregnancies; the study evaluated the relation between one or more of the aforementioned risk factors and the outcome of pre-eclampsia; the authors provided the number of pre-eclampsia events among their participants with and without a given risk factor, to enable the calculation of pooled effect sizes, as described below.

Full text papers were included in the final dataset if they met the aforementioned screening criteria and also evaluated each risk factor up to 16 weeks' gestation or earlier (as aspirin might be more efficacious when initiated before this gestational age $\left.{ }^{6-8}\right)$.

Two authors (EB and KM), both of whom are medical students, screened studies and abstracted data. EB screened all citations retrieved from the database searches, and both authors evaluated the eligibility of the full text articles. Disagreements were resolved by discussion or in consultation with a third author (JGR). If two published studies evaluated the same cohort of women, we included the study with the largest number of women or the greatest number of relevant outcomes. Study authors were not contacted.

\section{Data abstraction from eligible studies}

Two reviewers (EB and KM) independently abstracted data using standardized tables. The first table considered the characteristics of each study, such as setting, inclusion/exclusion criteria, sample size, and the definition of pre-eclampsia. In a second table, we recorded the proportion of women who developed pre-eclampsia in the presence and absence of each given risk factor. We then generated an unadjusted relative risk for each risk factor in each study. When available, we also recorded the fully adjusted risk, hazard ratio, or odds ratio that was provided by the study authors for each respective risk factor.

\section{Data analysis}

For each risk factor, we first calculated the pooled pre-eclampsia event rate in the exposed and unexposed groups, using an arcsine transformation. As statistical heterogeneity was evident across studies, we used a DerSimonian-Laird binary random effects model to derive a pooled relative risk $\left(R_{\text {pooled }}\right)$ and $95 \%$ confidence interval for each risk factor. For the calculated pooled relative risk for each risk factor, we assessed heterogeneity by $\mathrm{I}^{2}$.

Using the pooled relative risks, we calculated the population attributable fraction (PAF) for each risk factor, with the following formula:

$$
\mathrm{PAF}=\left[\mathrm{P}_{\text {epooled }}\left(\mathrm{RR}_{\text {pooled }}-1\right)\right] /\left[\mathrm{P}_{\text {epooled }}\left(\mathrm{RR}_{\text {pooled }}-1\right)+1\right]
$$

where $\mathrm{P}_{\text {epooled }}$ is the number of women with a given risk factor in each study divided by the total number of women in that same study, pooled across studies using the arcsine transformation, and where $\mathrm{RR}_{\text {pooled }}$ is the 
pooled relative risk calculated above. We used OpenMeta[Analyst] (Providence, RI) for all meta-analyses.

We performed three additional analyses that were limited to three chosen risk factors-namely prior pre-eclampsia (representing a risk factor arising in a prior pregnancy), chronic hypertension (a risk factor identified in the current pregnancy), and prepregnancy BMI $>30$ (a risk factor measured early in the current pregnancy). For each of these risk factors we had a sufficient number of studies to enable these further analyses. First, in a sensitivity analysis, we re-calculated the pooled relative risk using data limited to prospective studies, which tend to have more accurate ascertainment of risk factors and outcomes and also less biased effect sizes. ${ }^{22}$ Second, we constructed three funnel plots to assess publication bias. Third, in a post hoc analysis, we determined the agreement between our calculated crude relative risks and the adjusted relative risks originally published in each study, expressed as an $\mathrm{R}^{2}$ and 95\% confidence interval. If adjusted odds ratios were originally presented, then we derived adjusted relative risks using the formula provided by Zhang and $\mathrm{Yu}^{23}$

Sinclair and colleagues previously described the threshold number needed to treat $\left(\mathrm{NNT}_{\mathrm{T}}\right)$ and minimum event rate for treatment (MERT). ${ }^{24}$ The minimum event rate for treatment-the minimum disease event rate that justifies offering a given treatment-is a function of both the threshold number needed to treat and the relative risk reduction (that is, efficacy) conferred by the treatment. We adapted their approach ${ }^{24}$ to calculate the threshold number needed to prevent $\left(\mathrm{NNP}_{\mathrm{T}}\right)$ with aspirin in the presence of a given risk factor for pre-eclampsia-that is, the maximum number of women with the risk factor in whom one would be willing to give aspirin to prevent one case of pre-eclampsia, using the following formula:

$$
\mathrm{NNP}_{\mathrm{T}}=1 /\left(\mathrm{EER}^{\star} \mathrm{RRR}\right),
$$

where EER is the pooled event rate of pre-eclampsia in the exposed group as calculated above for each risk factor and RRR (relative risk reduction) is the established efficacy of aspirin, with reported relative risk reductions of $10 \%, 30 \%$, or $50 \%$ in various meta-analyses. ${ }^{3-5}$ We previously showed that a conservative estimate of the $\mathrm{NNP}_{\mathrm{T}}$ for aspirin prophylaxis is about 250 women, assuming a modest gain of 0.05 quality adjusted life years (see http://www.ncbi.nlm.nih.gov/ pmc/articles/PMC4366221/figure/pone.0116296.g001/ in our prior study ${ }^{25}$ ). If a risk factor on its own was shown to have a $\mathrm{NNP}_{\mathrm{T}}$ under 250 , especially at a small relative risk reduction of $10 \%$, then it might influence the decision to start aspirin prophylaxis.

\section{Patient involvement}

No patients were involved in setting the research question or the outcome measures, nor were they involved in developing plans for implementation of the study. No patients were asked to advise on interpretation or writing up of results. There are no plans to disseminate the results of the research to study participants or the relevant patient community.
Records identified through database searching $(n=4048)$ :

PubMed $(n=2567)$

Embase, excluding duplicates from PubMed $(n=1481)$ Titles and abstracts screened $(n=4048)$

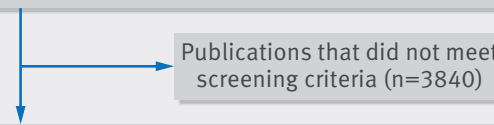

Full text articles retrieved and assessed for eligibility $(n=208)$

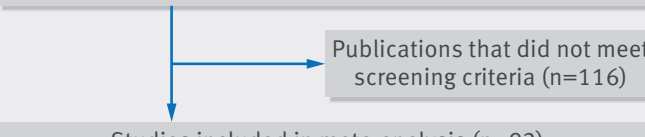

Studies included in meta-analysis $(n=92)$

Fig 1 | PRISMA flow diagram of selection and inclusion of studies in current meta-analysis of risk factor for pre-eclampsia

\section{Results}

Figure 1 shows the selection process for articles included in our systematic review and meta-analysis. There were 4048 non-duplicate potentially relevant citations (appendix 1). Of these, 208 publications met the screening criteria, and, after review of the full text articles, a total of 92 articles met our inclusion criteria $^{26-117}$ (appendix 2).

\section{Characteristics of included studies}

Appendix 2 shows the general study characteristics and sample characteristics of the included studies, comprising 25356688 pregnancies in 27 countries. There were 40 studies from Europe and 30 studies from North America. Of the 92 studies, 55 were retrospective and 37 were of a prospective cohort design. Sixty one studies used a standard clinical definition of pre-eclampsia, 16 used ICD (international classification of diseases) codes, and 15 provided no formal definition. The mean number of participants was 275616 (SD 704906), with a minimum of 1043 and a maximum of 4395968 . Fifty seven studies (62\%) were limited to singleton pregnancies, while out of 92 studies, nine $(9.8 \%)$ excluded stillbirths and 18 (19.6\%) excluded congenital anomalies. Twenty four studies documented participant attrition, which was about $3 \%$ on average (appendix 2).

\section{Quantitative data synthesis}

Figure 2 shows the pooled event rates for pre-eclampsia in the exposed and unexposed groups, according to each risk factor. In the unexposed groups, for each specific risk factor, the pooled pre-eclampsia event rate was always under 5\%. The weighted mean pooled event rate for all risk factors was $2.7 \%$ (SD 0.93\%) across all unexposed groups, in contrast with a weighted mean rate of 7.3\% (SD 4.6\%) across all exposed groups.

The pooled relative risk for each risk factor was significantly greater than 1.0, with the exception of a history of prior intrauterine growth restriction, which was based on one study with 55542 participants (fig 2 and appendix 3). Although women with antiphospholipid antibody syndrome had the highest pooled rate 


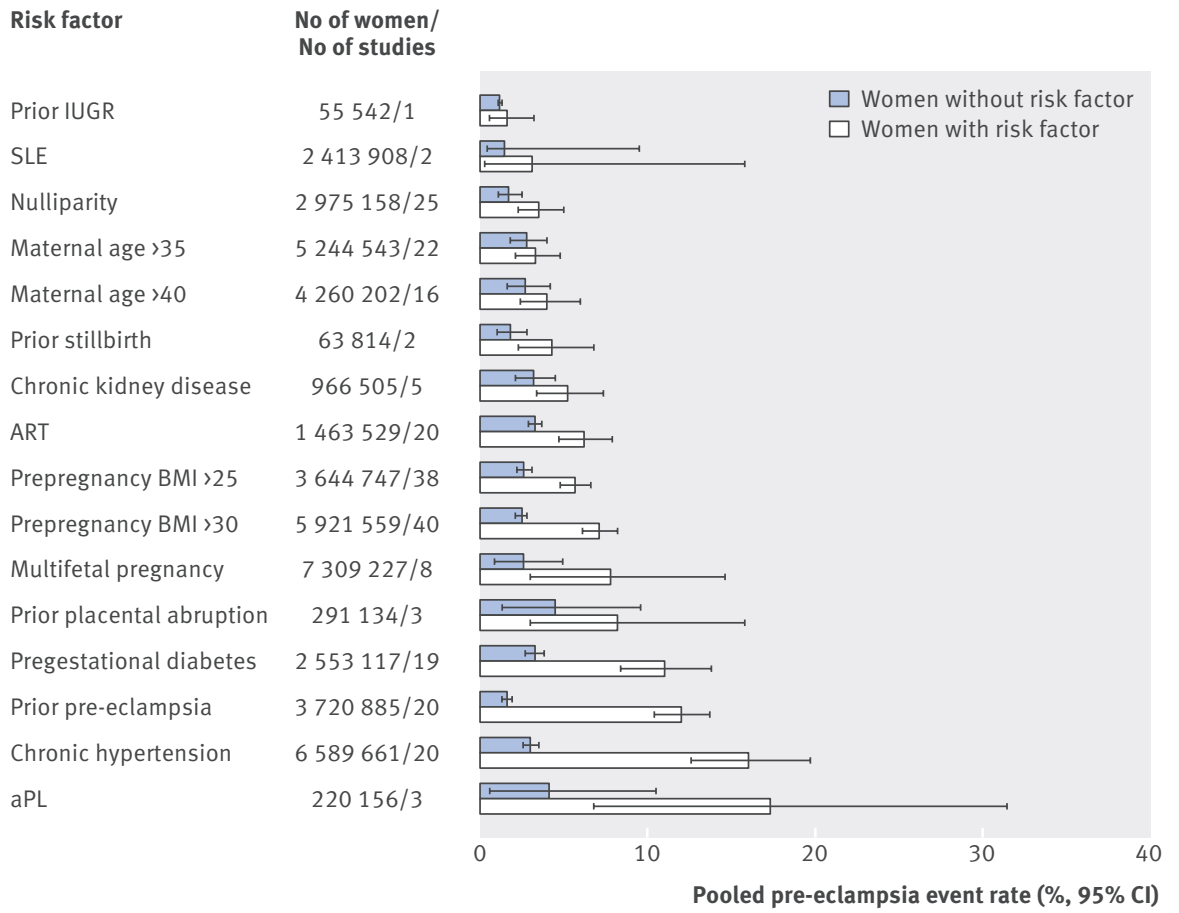

$I^{2} \quad$ Pooled unadjusted relative risk $(95 \% \mathrm{CI})$

N/A 1.4 (0.6 to 3.0)

$71 \quad 2.5$ (1.0 to 6.3)

$90 \quad 2.1$ (1.9 to 2.4 )

$92 \quad 1.2$ (1.1 to 1.3$)$

$95 \quad 1.5$ (1.2 to 2.0$)$

$0 \quad 2.4$ (1.7 to 3.4$)$

$44 \quad 1.8$ (1.5 to 2.1)

$79 \quad 1.8(1.6$ to 2.1$)$

$89 \quad 2.1$ (2.0 to 2.2)

$98 \quad 2.8$ (2.6 to 3.1)

$67 \quad 2.9$ (2.6 to 3.1)

$61 \quad 2.0$ (1.4 to 2.7 )

$79 \quad 3.7$ (3.1 to 4.3)

$96 \quad 8.4$ (7.1 to 9.9)

$98 \quad 5.1$ (4.0 to 6.5$)$

$0 \quad 2.8$ (1.8 to 4.3 )

Pooled pre-eclampsia event rate $(\%, 95 \% \mathrm{Cl})$

Fig 2 | Risk of pre-eclampsia among women with and without individual clinical risk factors determined by 16 weeks' gestation. IUGR=intrauterine growth restriction; $S L E=$ systemic lupus erythematosus; $A R T=$ assisted reproductive technology; $\mathrm{BMI}=$ body mass index; $\mathrm{aPL}=$ antiphospholipid antibody syndrome; $\mathrm{N} / \mathrm{A}=$ not applicable

of pre-eclampsia $(17.3 \%$, 95\% confidence interval $6.8 \%$ to $31.4 \%$ ), those with prior pre-eclampsia had the greatest pooled relative risk $(8.4,95 \%$ confidence interval 7.1 to 9.9). Chronic hypertension ranked second, both for the pooled rate $(16.0 \%, 12.6 \%$ to $19.7 \%)$ and pooled relative risk (5.1, 4.0 to 6.5 ) of pre-eclampsia. As indicated by the $\mathrm{I}^{2}$ values, there was a high level of heterogeneity for the pooled relative risk for most risk factors (fig 2). The definition of chronic hypertension varied by study-for example, Anderson and colleagues defined chronic hypertension as hypertension before 20 weeks' gestation or a medical history of essential hypertension, ${ }^{28}$ while Basso and colleagues defined it as self reported pre-existing hypertension, ${ }^{30}$ and Magnussen and colleagues used a measured prepregnancy blood pressure above 140/90 mm Hg. ${ }^{71}$ When we examined studies of chronic hypertension, the pooled rate of pre-eclampsia was $16.0 \%$ (15.2\% to $16.7 \%)$ among women with chronic hypertension in studies in which pre-eclampsia was based on a standard clinical definition, compared with 5.9\% (5.7\% to 6.2\%) among women with chronic hypertension in studies in which pre-eclampsia was based on ICD coding. In the same studies, however, among women without hypertension, the respective pooled rates of pre-eclampsia were 3.1\% (3.1\% to $3.1 \%$ ) and $2.7 \%$ (2.7\% to $2.7 \%$ ). Likewise, in women whose BMI was $\geq 30$ the pooled rate of pre-eclampsia was $5.1 \%$ (5.0\% to $5.2 \%$ ) with ICD coding versus $7.7 \%(7.6 \%$ to $7.8 \%)$ with a standard clinical definition, contrasted by respective pooled rates of pre-eclampsia of $2.0 \%$ (2.0\% to $2.0 \%)$ and $2.8 \%$ (2.7\% to $2.8 \%$ ) in women with $\mathrm{BMI}<30$.
Nulliparity had the greatest population attributable fraction for pre-eclampsia (32.3\%, 95\% confidence interval $27.4 \%$ to $37.0 \%$ ), followed by prepregnancy BMI $>25(23.8 \%, 22.0 \%$ to $25.6 \%)$ and prior pre-eclampsia (22.8\%, 19.6\% to $26.3 \%$ ) (fig 3). Antiphospholipid antibody syndrome had one of the lowest population attributable fractions $(0.18 \%, 0.08 \%$ to $0.33 \%)$.

\section{Additional analyses}

In the sensitivity analysis limited to prospective cohort studies, the pooled relative risk for prior pre-eclampsia (7.4, 95\% confidence interval 5.9 to 9.5 ), chronic hypertension (5.4, 4.2 to 7.0), and prepregnancy BMI >30 (2.7, 2.5 to 2.9 ) did not differ appreciably from the pooled relative risk based on prospective and retrospective cohort studies together (fig 2).

The funnel plot for each of the three risk factors was generally symmetrical but contained many points outside of the pseudo $95 \%$ confidence intervals, especially at low standard errors (appendix 4).

In the post hoc analysis, the $\mathrm{R}^{2}$ agreement between our calculated crude relative risks and the originally published adjusted relative risks was 0.81 (95\% confidence interval 0.60 to 1.00) for prior pre-eclampsia, 0.78 (0.54 to 1.00) for chronic hypertension, and 0.75 (0.58 to 0.91 ) for prepregnancy BMI $>30$.

\section{Application of findings to identify "high risk"} women who could benefit from aspirin prophylaxis The threshold number needed (upper 95\% confidence interval) for aspirin prophylaxis to prevent one case of pre-eclampsia varied by risk factor and by the expected efficacy of aspirin (fig 4). Considering each risk factor 
and its pooled pre-eclampsia event rate, and assuming a conservative $10 \%$ relative risk reduction conferred by aspirin, we found that antiphospholipid antibody syndrome, chronic hypertension, prior pre-eclampsia, pregestational diabetes mellitus, prepregnancy BMI

$\begin{array}{lcc}\text { Risk factor } & \begin{array}{c}\text { No of women/ } \\ \text { No of studies }\end{array} \\ \text { SLE } & 2413908 / 2 \\ \text { aPL } & 220156 / 3 \\ \text { Prior IUGR } & 55542 / 1 \\ \text { Prior placental abruption } & 291134 / 3 \\ \text { Prior stillbirth } & 63814 / 2 \\ \text { Pregestational diabetes } & 2553117 / 19 \\ \text { Chronic kidney disease } & 966505 / 5 \\ \text { Maternal age }>40 & 4260202 / 16 \\ \text { Maternal age }>35 & 5244543 / 22 \\ \text { ART } & 1463529 / 20 \\ \text { Multifetal pregnancy } & 7309227 / 8 \\ \text { Chronic hypertension } & 6589661 / 20 \\ \text { Prior pre-eclampsia } & 3720885 / 20 \\ \text { Prepregnancy BMI } 330 & 5921559 / 40 \\ \text { Prepregnancy BMI }>25 & 3644747 / 38 \\ \text { Nulliparity } & 2975158 / 25 \\ & \end{array}$

Fig 3 | Population attributable fraction for pre-eclampsia in relation to individual clinical risk factors determined by 16 weeks' gestation. IUGR=intrauterine growth restriction; $\mathrm{SLE}=$ systemic lupus erythematosus; $\mathrm{ART}=$ =assisted reproductive technology; $\mathrm{BMI}=$ body mass index; $\mathrm{aPL}=$ antiphospholipid antibody syndrome

$\begin{array}{lclll}\text { Risk factor } & \begin{array}{c}\text { No of women/ } \\ \text { No of studies }\end{array} \\ \text { aPL } & 220156 / 3 \\ \text { Chronic hypertension } & 6589661 / 20 \\ \text { Prior pre-eclampsia } & 3720885 / 20 \\ \text { Pregestational diabetes } & 2553117 / 19 \\ \text { Prior placental abruption } & 291134 / 3 \\ \text { Multifetal pregnancy } & 7309227 / 8 \\ \text { Prepregnancy BMI >30 } & 5921559 / 40 \\ \text { ART } & 1463529 / 20 \\ \text { Chronic kidney disease } & 966505 / 5 \\ \text { Prior stillbirth } & 63814 / 2 \\ \text { Maternal age } \text { 40 } & 4260202 / 16 \\ \text { Nulliparity } & 2975158 / 25 \\ \text { SLE } & 2413908 / 2 \\ \text { Prior IUGR } & 55542 / 1\end{array}$

Fig 4 | Threshold number of women needed to receive aspirin prophylaxis to prevent one case of pre-eclampsia, based on individual clinical risk factors determined by 16 weeks' gestation. Dashed line is clinically important minimum $\mathrm{NNP}_{\mathrm{T}}$ of 250 women. ${ }^{25}$

IUGR=intrauterine growth restriction; $S L E=$ systemic lupus erythematosus; $A R T=$ assisted reproductive technology; $\mathrm{BMI}=$ body mass index; $\mathrm{aPL}=$ antiphospholipid antibody syndrome
$>30$, and assisted reproductive technology each had a threshold number needed to prevent with an upper 95\% confidence interval well below the clinically important figure of 250 (fig 4, broken line). At a 30\% and 50\% relative risk reduction, the remaining risk factors were below the threshold of 250, with the exception of systemic lupus erythematosus and prior intrauterine growth restriction (fig 4).

\section{Discussion \\ Main findings}

Based on a body of large sample cohort studies, we estimated the contributions of several clinical risk factors to the development of pre-eclampsia, considering the absolute rate and relative risk of pre-eclampsia-metrics understood by clinicians-and also on the population attributable fraction-a metric applicable to public health initiatives at the population level. Except for a history of intrauterine growth restriction, each identified risk factor was associated with a significantly heightened risk of pre-eclampsia. Some risk factors, including antiphospholipid antibody syndrome, prior pre-eclampsia, chronic hypertension, pre-gestational diabetes, and BMI $>30$, were also strongly associated with a high rate of pre-eclampsia. We used the example of aspirin prophylaxis to show how these risk factors can inform a pre-eclampsia prevention program.

\section{Strengths and limitations}

We pooled data from studies of more than 25 million women, enabling us to systematically evaluate several well defined risk factors that have been largely accepted in most clinical settings and within published clinical practice guidelines. ${ }^{9-11}$ Our inclusion of only large sample cohort studies helped curtail the bias potentially introduced by smaller studies ${ }^{21}$ but by no means eliminated the risk of participant selection bias. Many of the cohort studies we included were population based (appendix 2), thereby avoiding small audit based or single centre studies that could be more prone to selection bias. When we limited our analysis to prospective cohort studies, which tend to have less selection bias, the pooled relative risks did not differ appreciably from those in the main analysis. Our determination of the risk of pre-eclampsia was better informed for some risk factors than for others (such as prior intrauterine growth restriction or systemic lupus erythematosus), which were based on only one or two contributing studies and a lower overall number of participants. Other risk factors (such as maternal age $>40$ ) were evaluated from a sufficient number of studies and pregnancies but still surpassed the threshold number needed to prevent of 250. We did not evaluate family history of pre-eclampsia, for the reasons stated above, ${ }^{20}$ but it is certainly worthy of additional exploration as a risk factor.

By restricting our analyses to studies examining risk factors determined in early pregnancy, we focused on risk factors that could lead to a timely intervention, such as aspirin prophylaxis..$^{6-8}$ We generated reliable and consistent results across studies, as most were completed in the past two decades within Western 
countries, and about two thirds used a standard clinical definition of pre-eclampsia. This was evidenced by a $2.7 \%$ weighted mean event rate for all risk factors across all unexposed groups, a figure close to that estimated within Western countries. ${ }^{118}$ Certainly in low income countries, where the rate of pre-eclampsia tends to be higher ${ }^{12}$ and the prevalence of risk factors might differ, less can be said about the behavior of the currently evaluated risk factors for pre-eclampsia.

As a limitation, 15 out of 92 studies did not provide a formal definition of pre-eclampsia, our main outcome. When the outcome was based on a standard clinical definition, the rate of pre-eclampsia was much higher than rates based on ICD coding, as noted for women with chronic hypertension and women with a BMI $\geq 30$. Another inconsistency was in the differing definitions of certain risk factors. "Renal disease," for example, ranged from mild to severe loss of renal function. Similarly, the definition of chronic hypertension or antiphospholipid antibody syndrome varied by study or era, or both. Notwithstanding that limitation, antiphospholipid antibody syndrome and chronic hypertension were apparent individual risk factors for pre-eclampsia, and chronic kidney disease was likely the same. Certainly, varying definitions of a given risk factor and/or pre-eclampsia could produce heterogeneity in our associated risk estimates. Moreover, as several of our included large population based cohort studies relied on ICD coding for risk factors and pre-eclampsia, their influence would be expected to underestimate the pooled pre-eclampsia event rates or the pooled relative risk for a given risk factor and pre-eclampsia. In addition, some risk factors can heighten the risk of pre-eclampsia in a dose-response manner. Therefore, dichotomizing those risks might be inappropriate. For instance, a woman whose BMI is 29 might have a risk of pre-eclampsia that is comparable with a woman whose BMI is 31. Our funnel plots showed a small degree of asymmetry, which would suggest publication bias. It can, however, be difficult to assess publication bias when effect sizes are highly heterogeneous, ${ }^{119}$ as was the case here. Moreover, our use of a random effects model could explain why many points in the funnel plots were outside of the pseudo 95\% confidence intervals ${ }^{120}$ (appendix 4). We observed a high level of heterogeneity for the pooled relative risk values. Some degree of heterogeneity is to be expected, however, and could actually increase the generalizability of a meta-analysis over single studies. ${ }^{121}$

In meta-analyses of observational studies, variation can be caused by measurement bias, selection bias, confounding, and differences in effect modification. ${ }^{122}$ While only 24 of 92 studies described participant attrition, the average rate was just $3 \%$, suggesting that attrition is uncommon in obstetrical studies, where the duration of follow-up is typically under 40 weeks. In our analyses, we used bivariate data to calculate the pooled event rates, pooled relative risk, and population attributable fraction. Accordingly, we could not account for the interaction between one risk factor and another. For prior pre-eclampsia, chronic hypertension, and prepregnancy BMI $>30$, we found good agreement between the calculated unadjusted relative risks and the reported adjusted relative risks. In addition, our calculated rate of pre-eclampsia in women with prior pre-eclampsia based on aggregate data $(12.0 \%, 95 \%$ confidence interval $10.4 \%$ to $13.7 \%$ ) was similar to that in a recent meta-analysis of individual patient data $(13.8 \%, 13.6 \%$ to $14.1 \%) .123$ None of the risk factors we evaluated would be particularly susceptible to recall bias, especially those that were measured in the current pregnancy. Even for the risk factor of prior pre-eclampsia, cohort studies have observed a sensitivity of $73-87 \%$ and a specificity greater than $95 \%$ for recalling the condition at some later period. ${ }^{124}$ While this offers some degree of re-assurance that our current analytical approach provided precise and unbiased estimates of the rate of pre-eclampsia, a meta-analysis of individual patient data from cohort studies and randomized clinical trials (for example, of aspirin prophylaxis ${ }^{13}$ ) could assess the veracity of this statement.

\section{Interpretation}

By quantifying the risk of pre-eclampsia conferred by various individual clinical risk factors, a clinician could be better equipped to estimate a woman's risk of pre-eclampsia and her candidacy for heightened surveillance or prophylactic measures, including aspirin. Additionally, our findings could enhance the choice and weighting of first trimester clinical factors in future clinical prediction models for pre-eclampsia. ${ }^{125}$

At a population health level, the population attributable fractions we calculated suggest different priority of risk factors for pre-eclampsia, only some of which are modifiable (fig 3). For example, nulliparity is not reversible, while prepregnancy obesity is. Moreover, as obesity is closely linked to chronic hypertension, ${ }^{126}$ a reduction in prepregnancy BMI could reduce both of these important risk factors for pre-eclampsia. Certainly, in women with non-modifiable risk factors, such as a prior history of pre-eclampsia, one could consider alternative strategies. The example we used was aspirin prophylaxis, which has been shown to efficaciously and safely reduce the risk of pre-eclampsia in high risk women. ${ }^{914}$ Some risk factors - antiphospholipid antibody syndrome, chronic hypertension, prior pre-eclampsia, pregestational diabetes mellitus, prepregnancy BMI $>30$, and assisted reproductive technology-were each found to be associated with a high rate of pre-eclampsia and a low threshold number needed to prevent $\left(\mathrm{NNP}_{\mathrm{T}}\right)$, which would justify consideration for aspirin (fig 4). Outside of pregnancy, for example, 420 adult women need to be treated with aspirin over five years to prevent one cardiovascular event. ${ }^{127}$ We adopted a much more conservative approach, setting the $\mathrm{NNP}_{\mathrm{T}}$ at 250 , knowing that women need to take aspirin for only 25 weeks to prevent a single case of pre-eclampsia. It is on this basis that certain risk factors, either alone or in combination, might be enough to label a woman as being at "high risk" for pre-eclampsia. For others, we either lacked confidence about their role as a distinct risk factor for pre-eclampsia, or they simply surpassed $\mathrm{NNP}_{\mathrm{T}}$ of 250 . Notwithstanding, we believe that all of the risk factors we studied should be evaluated within a multivariable model examining the 
risk of pre-eclampsia, with various combinations of risk factors. For prior intrauterine growth restriction, itself a heterogeneous state, ${ }^{128}$ its role as a risk factor for pre-eclampsia remains to be determined with a standard and specific definition.

The main goal of our meta-analysis was to identify those clinical risk factors that serve as potential determinants of pre-eclampsia. Schnohr and colleagues used a similar approach in ranking the top 10 risk factors for coronary heart disease. ${ }^{129}$ They found that their prioritization of risk factors differed at the individual patient level (based on the relative risk) from that at the population level (based on the population attributable fraction). ${ }^{129}$ This dual approach is attractive, as a woman with a rare risk factor like antiphospholipid antibody syndrome is certainly at high risk of pre-eclampsia in the presence of that risk factor (fig 2), even though the rarity of that risk factor makes it less of a consideration in the reduction of risk of pre-eclampsia within the entire population (fig 3). Moreover, they used a multivariable approach in their analysis of risk factors for coronary heart disease, something to be considered in the comparison of the influence of risk factors for pre-eclampsia.

\section{Conclusion}

We identified the extent to which various clinical risk factors in early pregnancy heighten a woman's absolute and relative risk for pre-eclampsia. Some of the major risk factors evaluated produced event rates that were either similar to, or lower than, the rates seen in randomized controlled trials of aspirin prophylaxis among women at risk of pre-eclampsia'13-19 (appendix 5). Accordingly, evaluation of whether the efficacy (that is, relative risk reduction) of aspirin prophylaxis differs across risk factors can clarify whether they are equally responsive to that intervention, or others. Additionally, evaluation of the effectiveness of aspirin in the prevention of preterm pre-eclampsia and severe forms of pre-eclampsia, by individual risk factors and their combination, is needed. Separately, there is evidence that clinical decisions are viewed differently by a woman and her healthcare provider, ${ }^{130}$ as is their perception of risk. ${ }^{131} 132$ Thus, data should be obtained from the woman and practitioner on the threshold number needed to prevent at which they are comfortable initiating aspirin prophylaxis.

Members of the High Risk of Pre-eclampsia Identification Group Ziad TA Al-Rubaie (The University of Notre Dame Australia, Sydney, Australia), Lisa M Askie (NHMRC Clinical Trials Centre, University of Sydney), EB (University of Toronto), Howard Berger (head, maternal fetal medicine and obstetric ultrasound, department of obstetrics and gynecology, St Michael's Hospital, Toronto), Jennifer Blake (chief executive officer, Society of Obstetricians and Gynecologists of Canada), Lisa Graves (Western Michigan University Homer Stryker M.D. School of Medicine), John C Kingdom (Gordon C Leitch chair, department of obstetrics and gynecology, University of Toronto), Gerald Lebovic (Applied Health Research Centre, St Michael's Hospital, Toronto), Sally J Lord (University of Notre Dame Australia: NHMRC Clinical Trials Centre, University of Sydney), Jonathon L Maguire (departments of pediatrics and health policy, management and evaluation, St Michael's Hospital, University of Toronto), Muhammad M Mamdani (Li Ka Shing Knowledge Institute of St Michael's Hospital, University of Toronto, Toronto, Ontario), KM (University of Toronto), James Meloche (executive director, Provincial
Council for Maternal and Child Health, Toronto), ALP (Institute for Clinical Evaluative Sciences, Toronto), JGR (departments of medicine, health policy management and evaluation, and obstetrics and gynecology, St Michael's Hospital, University of Toronto), Marcelo L Urquia (Li Ka Shing Knowledge Institute of St Michael's Hospital, University of Toronto), Vicki Van Wagner (Midwifery Education Program, Ryerson University, Toronto).

Contributors: EB and JGR were responsible for study concept, analyzed and interpreted the data, drafted and revised the manuscript, and approved the final version. KM and ALP analyzed and interpreted the data, revised the manuscript, and approved the final version. All members of the High Risk of Pre-eclampsia Identification Group were involved in study concept, revised the manuscript, and approved the final version. EB and JGR are guarantors.

Funding: This work was supported by a Knowledge Synthesis grant from the Canadian Institutes for Health Research. JGR holds a Canadian Institutes for Health Research Chair in Reproductive and Child Health Services and Policy Research.

Competing interests: All authors have completed the ICMJE uniform disclosure form at www.icmje.org/coi_disclosure.pdf and declare: no support from any organization for the submitted work; no financial relationships with any organizations that might have an interest in the submitted work in the previous three years; no other relationships or activities that could appear to have influenced the submitted work. Ethical approval: Not required.

Data sharing: No additional data available.

Transparency: The lead authors (EB and JGR) affirm that the manuscript is an honest, accurate, and transparent account of the study being reported; that no important aspects of the study have been omitted; and that any discrepancies from the study as planned (and, if relevant, registered) have been explained.

This is an Open Access article distributed in accordance with the Creative Commons Attribution Non Commercial (CC BY-NC 3.0) license, which permits others to distribute, remix, adapt, build upon this work non-commercially, and license their derivative works on different terms, provided the original work is properly cited and the use is noncommercial. See: http://creativecommons.org/licenses/by-nc/3.0/.

1 English FA, Kenny LC, McCarthy FP. Risk factors and effective management of preeclampsia. Integr Blood Press Control 2015;8:7-12

2 Sibai B, Dekker G, Kupferminc M. Pre-eclampsia. Lancet 2005:365:785-99. doi:10.1016/S0140-6736(05)71003-5.

3 Duley L, Henderson-Smart DJ, Meher S, King JF. Antiplatelet agents for preventing pre-eclampsia and its complications. Cochrane Database Syst Rev 2007;2:CD004659

4 CLASP (Collaborative Low-dose Aspirin Study in Pregnancy) Collaborative Group. CLASP: a randomised trial of low-dose aspirin for the prevention and treatment of pre-eclampsia among 9364 pregnant women. Lancet 1994;343:619-29. doi:10.1016/

S0140-6736(94)92633-6

5 Sibai BM, Caritis SN, Thom E, Shaw K, McNellis D. National Institute of Child Health and Human Developmental Maternal-Fetal Medicine Network. Low-dose aspirin in nulliparous women: safety of continuous epidural block and correlation between bleeding time and maternal-neonatal bleeding complications. Am J Obstet Gynecol 1995:172:1553-7. doi:10.1016/0002-9378(95)90495-6.

6 Bujold E, Roberge S, Lacasse Y, et al. Prevention of preeclampsia and intrauterine growth restriction with aspirin started in early pregnancy: a meta-analysis. Obstet Gynecol 2010;116:402-14. doi:10.1097/ AOG Ob013e3181e9322a.

7 Roberge S, Nicolaides KH, Demers S, Villa P, Bujold E. Prevention of perinatal death and adverse perinatal outcome using low-dose aspirin: a meta-analysis. Ultrasound Obstet Gynecol 2013;41:491-9. doi:10.1002/uog.12421.

8 Roberge S, Villa P, Nicolaides K, et al. Early administration of low-dose aspirin for the prevention of preterm and term preeclampsia: a systematic review and meta-analysis. Fetal Diagn Ther 2012;31:141-6. doi:10.1159/000336662.

9 National Collaborating Centre for Women's and Children's Health (UK). Hypertension in Pregnancy: The Management of Hypertensive Disorders During Pregnancy. National Institute for Health and Clinical Excellence: Guidance. 2010.

10 Henderson IT, Whitlock EP, O'Connor E, Senger CA, Thompson JH, Rowland MG. Low-dose aspirin for prevention of morbidity and mortality from preeclampsia: a systematic evidence review for the U.S. Preventive Services Task Force. Ann Intern Med 2014;160:695703. doi:10.7326/M13-2844.

11 Lausman A, Kingdom J, Gagnon R, et al. Maternal Fetal Medicine Committee. Intrauterine growth restriction: screening, diagnosis, and management. J Obstet Gynaecol Can 2013;35:741-48. doi:10.1016/ S1701-2163(15)30865-3. 
12 Sibai BM, Caritis SN, Thom E, et al. The National Institute of Child Health and Human Development Network of Maternal-Fetal Medicine Units. Prevention of preeclampsia with low-dose aspirin in healthy, nulliparous pregnant women. N Engl J Med 1993;329:1213-8. doi:10.1056/NEJM199310213291701

13 Askie LM, Duley L, Henderson-Smart DJ, Stewart LA. PARIS Collaborative Group. Antiplatelet agents for prevention of pre-eclampsia: a meta-analysis of individual patient data. Lancet 2007:369:1791-8. doi:10.1016/S0140-6736(07)60712-0.

14 Verghese L, Alam S, Beski S, Thuraisingham R, Barnes I, MacCallum P. Antenatal screening for pre-eclampsia: evaluation of the NICE and pre-eclampsia community guidelines. J Obstet Gynaecol 2012;32:12831. doi:10.3109/01443615.2011.635224.

15 Cnossen JS, ter Riet G, Mol BW, et al. Are tests for predicting pre-eclampsia good enough to make screening viable? A review of reviews and critical appraisal. Acta Obstet Gynecol Scand 2009:88:758-65. doi:10.1080/00016340903008953.

16 Ruano R, Fontes RS, Zugaib M. Prevention of preeclampsia with low-dose aspirin -- a systematic review and meta-analysis of the main randomized controlled trials. Clinics (Sao Paulo) 2005;60:407-14. doi:10.1590/S1807-59322005000500010.

17 Ray JG, Vermeulen MJ, Schull MJ, Redelmeier DA. Cardiovascular health after maternal placental syndromes (CHAMPS): populationbased retrospective cohort study. Lancet 2005;366:1797-803. doi:10.1016/S0140-6736(05)67726-4.

18 Tikkanen M. Placental abruption: epidemiology, risk factors and consequences. Acta Obstet Gynecol Scand 2011;90:140-9. doi:10.1111/j.1600-0412.2010.01030.x

19 Xiong X, Mayes D, Demianczuk N, et al. Impact of pregnancy-induced hypertension on fetal growth. Am J Obstet Gynecol 1999;180:207-13. doi:10.1016/S0002-9378(99)70176-6

20 Wilson BJ, Qureshi N, Santaguida P, et al. Systematic review: family history in risk assessment for common diseases. Ann Intern Med 2009:151:878-85. doi:10.7326/0000605-200912150-00177.

21 Sterne JA, Gavaghan D, Egger M. Publication and related bias in meta-analysis: power of statistical tests and prevalence in the literature. / Clin Epidemiol 2000;53:1119-29. doi:10.1016/ S0895-4356(00)00242-0.

22 Euser AM, Zoccali C, Jager KJ, Dekker FW. Cohort studies: prospective versus retrospective. Nephron Clin Pract 2009;113:c214-7. doi:10.1159/000235241.

23 Zhang J, Yu KF. What's the relative risk? A method of correcting the odds ratio in cohort studies of common outcomes. JAMA 1998;280:1690-1. doi:10.1001/jama.280.19.1690.

24 Sinclair JC, Cook RJ, Guyatt GH, Pauker SG, Cook DJ. When should an effective treatment be used? Derivation of the threshold number needed to treat and the minimum event rate for treatment / Clin Epidemiol 2001:54:253-62. doi:10.1016/S0895-4356(01)00347-X.

25 Bartsch E, Park AL, Kingdom JC, Ray JG. Risk threshold for starting low dose aspirin in pregnancy to prevent preeclampsia: an opportunity at a low cost. PLoS One 2015;10:e0116296. doi:10.1371/journal. pone.0116296.

26 Al-Mulhim AA, Abu-Heija A, Al-Jamma F, El-Harith HA. Pre-eclampsia: maternal risk factors and perinatal outcome. Fetal Diagn Ther 2003:18:275-80 doi:10.1159/000070809.

27 Ananth CV, Peltier MR, Chavez MR, Kirby RS, Getahun D, Vintzileos AM. Recurrence of ischemic placental disease. Obstet Gyneco 2007:110:128-33. doi:10.1097/01.AOG.0000266983.77458.71.

28 Anderson NH, Sadler LC, Stewart AW, Fyfe EM, McCowan LM. Ethnicity, body mass index and risk of pre-eclampsia in a multiethnic New Zealand population. Aust N ZJ Obstet Gynaecol 2012;52:552-8. doi:10.1111/j.1479-828X.2012.01475.x

29 Baeten JM, Bukusi EA, Lambe M. Pregnancy complications and outcomes among overweight and obese nulliparous women. Am Public Health 2001:91:436-40. doi:10.2105/AIPH.91.3.436.

30 Basso O, Wilcox AJ, Weinberg CR, Baird DD, Olsen J. Height and risk of severe pre-eclampsia. A study within the Danish National Birth Cohort. Int JEpidemiol 2004:33:858-63. doi:10.1093/ije/dyh116.

31 Bautista-Castaño I, Henriquez-Sanchez P, Alemán-Perez N, et al. Maternal obesity in early pregnancy and risk of adverse outcomes. PLoS One 2013;8:e80410.pmid:24278281

32 Berlac JF, Skovlund CW, Lidegaard O. Obstetrical and neonatal outcomes in women following gastric bypass: a Danish national cohort study. Acta Obstet Gynecol Scand 2014;93:447-53. doi:10.1111/aogs.12368.

33 Bhattacharya S, Campbell DM, Liston WA, Bhattacharya S. Effect of Body Mass Index on pregnancy outcomes in nulliparous women delivering singleton babies. BMC Public Health 2007;7:168. doi:10.1186/1471-2458-7-168.

34 Black M, Shetty A, Bhattacharya S. Obstetric outcomes subsequent to intrauterine death in the first pregnancy. BJOG 2008;115:269-74. doi:10.1111/j.1471-0528.2007.01562.x

35 Blomberg M, Birch Tyrberg R, Kiølhede P. Impact of maternal age on obstetric and neonatal outcome with emphasis on primiparous adolescents and older women: a Swedish Medical Birth Register Study. BMJ Open 2014;4:e005840. doi:10.1136/ bmjopen-2014-005840.
36 Boghossian NS, Yeung E, Mendola P, et al. Risk factors differ between recurrent and incident preeclampsia: a hospital-based cohort study. Ann Epidemiol 2014:24:871-7e3. doi:10.1016/j. annepidem.2014.10.003

37 Boyd HA, Tahir H, Wohlfahrt J, Melbye M. Associations of personal and family preeclampsia history with the risk of early-, intermediate- and late-onset preeclampsia. Am J Epidemiol 2013;178:1611-9. doi:10.1093/aje/kwt189.

38 Brown MA, Mackenzie C, Dunsmuir W, et al. Can we predict recurrence of pre-eclampsia or gestational hypertension?BIOG 2007:114:984-93. doi:10.1111/j.1471-0528.2007.01376.x.

39 Carbone IF, Cruz JJ, Sarquis R, Akolekar R, Nicolaides KH. Assisted conception and placental perfusion assessed by uterine artery Doppler at 11-13 weeks' gestation. Hum Reprod 2011;26:1659-64. doi:10.1093/humrep/der117.

40 Catov JM, Ness RB, Kip KE, Olsen J. Risk of early or severe preeclampsia related to pre-existing conditions. Int J Epidemiol 2007;36:412-9. doi:10.1093/ije/dyl271.

41 Cedergren MI. Maternal morbid obesity and the risk of adverse pregnancy outcome. Obstet Gynecol 2004;103:219-24. doi:10.1097/01.AOG.0000107291.46159.00.

42 Chen XK, Wen SW, Bottomley J, Smith GN, Leader A, Walker MC. In vitro fertilization is associated with an increased risk for preeclampsia. Hypertens Pregnancy 2009;28:1-12. doi:10.1080/10641950802001859.

43 Croft ML, Morgan V, Read AW, Jablensky AS. Recorded pregnancy histories of the mothers of singletons and the mothers of twins: a longitudinal comparison. Twin Res Hum Genet 2010;13:595-603. doi:10.1375/twin.13.6.595.

44 Dayan N, Pilote L, Opatrny L, et al. Combined impact of high body mass index and in vitro fertilization on preeclampsia risk: a hospital-based cohort study. Obesity (Silver Spring) 2015;23:200-6. doi:10.1002/oby.20896.

45 Di Lorenzo G, Ceccarello M, Cecotti V, et al. First trimester maternal serum PIGF, free $\beta$-hCG, PAPP-A, PP-13, uterine artery Doppler and maternal history for the prediction of preeclampsia. Placenta 2012:33:495-501. doi:10.1016/i.placenta.2012.03.003.

46 Dokras A, Baredziak L, Blaine J, Syrop C, VanVoorhis BJ, Sparks A Obstetric outcomes after in vitro fertilization in obese and morbidly obese women. Obstet Gynecol 2006;108:61-9. doi:10.1097/01. AOG.0000219768.08249.b6.

47 El-Chaar D, Finkelstein SA, Tu X, et al. The impact of increasing obesity class on obstetrical outcomes. J Obstet Gynaecol Can 2013;35:22433. doi:10.1016/S1701-2163(15)30994-4

48 Eras JL, Saftlas AF, Triche E, Hsu CD, Risch HA, Bracken MB. Abortion and its effect on risk of preeclampsia and transient hypertension. Epidemiology 2000;11:36-43. doi:10.1097/00001648-200001000-00009.

49 Erez O, Vardi IS, Hallak M, Hershkovitz R, Dukler D, Mazor M. Preeclampsia in twin gestations: association with IVF treatments, parity and maternal age. J Matern Fetal Neonatal Med 2006;19:141-6. doi:10.1080/14767050500246045.

50 Fortner RT, Pekow P, Solomon CG, Markenson G, Chasan-Taber L. Prepregnancy body mass index, gestational weight gain, and risk of hypertensive pregnancy among Latina women. Am J Obstet Gynecol 2009;200:167.e1-7. doi:10.1016/j.ajog.2008.08.021.

51 Frederick IO, Rudra CB, Miller RS, Foster JC, Williams MA. Adult weight change, weight cycling and prepregnancy obesity in relation to risk of preeclampsia. Epidemiology 2006;17:428-34. doi:10.1097/01. ede.0000221028.33245.0b

52 Gaillard R, Bakker R, Steegers EAP, Hofman A, Jaddoe VW. Maternal age during pregnancy is associated with third trimester blood pressure level: the generation R study. Am J Hypertens 2011;24:1046 53. doi:10.1038/ajh.2011.95.

53 Gaillard R, Steegers EA, Hofman A, Jaddoe VW. Associations of maternal obesity with blood pressure and the risks of gestational hypertensive disorders. The Generation R Study. J Hypertens 2011:29:937-44. doi:10.1097/HJH.0b013e328345500c.

54 Gaio DS, Schmidt MI, Duncan BB, Nucci LB, Matos MC, Branchtein L. Hypertensive disorders in pregnancy: frequency and associated factors in a cohort of Brazilian women. Hypertens Pregnancy 2001:20:269-81. doi:10.1081/PRG-100107829.

55 Gilbert WM, Young AL, Danielsen B. Pregnancy outcomes in women with chronic hypertension: a population-based study. J Reprod Med 2007:52:1046-51.pmid:18161404

56 Goetzinger KR, Singla A, Gerkowicz S, Dicke JM, Gray DL, Odibo AO. Predicting the risk of pre-eclampsia between 11 and 13 weeks gestation by combining maternal characteristics and serum analytes, PAPP-A and free $\beta$-hCG. Prenat Diagn 2010;30:1138-42. doi:10.1002/ pd. 2627.

57 Hauger MS, Gibbons L, Vik T, Belizán JM. Prepregnancy weight status and the risk of adverse pregnancy outcome. Acta Obstet Gynecol Scand 2008;87:953-9. doi:10.1080/00016340802303349.

58 Hernández-Díaz S, Toh S, Cnattingius S. Risk of pre-eclampsia in first and subsequent pregnancies: prospective cohort study. BMJ 2009;338:b2255. doi:10.1136/bmj.b2255. 
59 Jacobsson B, Ladfors L, Milsom I. Advanced maternal age and adverse perinatal outcome. Obstet Gynecol 2004;104:727-33. doi:10.1097/01. AOG.0000140682.63746.be.

60 Jie Z, Yiling D, Ling Y. Association of assisted reproductive technology with adverse pregnancy outcomes. Iran / Reprod Med 2015;13:169-80.pmid:26000008.

61 Johnston R, Fong A, Lovell S, et al. Demographic and obstetric outcomes of pregnancies conceived by assisted reproductive technology (ART) compared to non-ART pregnancies. J Bras de Reproducao Assistida 2015;19:16-20.

62 Kenny LC, Black MA, Poston L, et al. Early pregnancy prediction of preeclampsia in nulliparous women, combining clinical risk and biomarkers: the Screening for Pregnancy Endpoints (SCOPE) international cohort study. Hypertension 2014;64:644-52. doi:10.1161/HYPERTENSIONAHA.114.03578.

63 Kerrigan AM, Kingdon C. Maternal obesity and pregnancy: a retrospective study. Midwifery 2010;26:138-46. doi:10.1016/j. midw.2008.12.005.

64 Khalil A, Syngelaki A, Maiz N, Zinevich Y, Nicolaides KH. Maternal age and adverse pregnancy outcome: a cohort study. Ultrasound Obstet Gynecol 2013;42:634-43. doi:10.1002/uog.12494.

65 Kuivasaari-Pirinen P, Raatikainen K, Hippelainen M, et alAdverse outcomes of IVF/ICSI pregnancies vary depending on aetiology of infertility. ISRN Obstet Gynecol 2012;2012:451915.

66 Lee CJ, Hsieh TT, Chiu TH, Chen KC, Lo LM, Hung TH. Risk factors for pre-eclampsia in an Asian population. Int J Gynaecol Obstet 2000:70:327-33. doi:10.1016/S0020-7292(00)00240-X

67 Li DK, Wi S. Changing paternity and the risk of preeclampsia/ eclampsia in the subsequent pregnancy. Am J Epidemiol 2000;151:5762. doi:10.1093/oxfordjournals.aje.a010122.

68 Liu S, Joseph KS, Liston RM, et al. Maternal Health Study Group of Canadian Perinatal Surveillance System (Public Health Agency of Canada). Incidence, risk factors, and associated complications of eclampsia. Obstet Gynecol 2011;118:987-94. doi:10.1097/ AOG.0b013e31823311c1.

69 Liu X, Du J, Wang G, Chen Z, Wang W, Xi Q. Effect of pre-pregnancy body mass index on adverse pregnancy outcome in north of China. Arch Gynecol Obstet 2011;283:65-70. doi:10.1007/ s00404-009-1288-5.

70 Luke B, Brown MB, Nugent C, Gonzalez-Quintero VH, Witter FR Newman RB. Risk factors for adverse outcomes in spontaneous versus assisted conception twin pregnancies. Fertil Steril 2004;81:315-9. doi:10.1016/j.fertnstert.2003.07.012.

71 Magnussen EB, Vatten LJ, Lund-Nilsen TI, Salvesen KA, Davey Smith G, Romundstad PR. Prepregnancy cardiovascular risk factors as predictors of pre-eclampsia: population based cohort study. BMJ 2007:335:978. doi:10.1136/bmi.39366.416817.BE.

72 Mahande MJ, Daltveit AK, Mmbaga BT, et al. Recurrence of preeclampsia in northern Tanzania: a registry-based cohort study. PLoS One 2013;8:e79116. doi:10.1371/journal.pone.0079116.

73 Martin CL, Hall MH, Campbell DM. The effect of smoking on pre-eclampsia in twin pregnancy. BJOG 2000;107:745-9. doi:10.1111/j.1471-0528.2000.tb13335.x

74 Mbah AK, Kornosky JL, Kristensen S, et al. Super-obesity and risk for early and late pre-eclampsia. BJOG 2010;117:997-1004 doi:10.1111/j.1471-0528.2010.02593.x.

75 Melamed N, Hadar E, Peled Y, Hod M, Wiznitzer A, Yogev Y. Risk for recurrence of preeclampsia and outcome of subsequent pregnancy in women with preeclampsia in their first pregnancy. J Matern Fetal Neonatal Med 2012;25:2248-51. doi:10.3109/14767058.2012.684174.

76 Munkhaugen J, Lydersen S, Romundstad PR, Widerøe TE, Vikse BE, Hallan S. Kidney function and future risk for adverse pregnancy outcomes: a population-based study from HUNT II, Norway. Nephrol Dial Transplant 2009;24:3744-50. doi:10.1093/ndt/ gfp320.

77 Ness RB, Zhang J, Bass D, Klebanoff MA. Interactions between smoking and weight in pregnancies complicated by preeclampsia and small-for-gestational-age birth. Am J Epidemiol 2008;168:427-33. doi:10.1093/aje/kwn140

78 Ngowa JD, Ngassam AN, Dohbit JS, Nzedjom C, Kasia JM. Pregnancy outcome at advanced maternal age in a group of African women in two teaching Hospitals in Yaounde, Cameroon. Pan Afr Med J 2013;14:134.pmid:23734279.

79 Nili F, McLeod L, O'Connell C, Sutton E, McMillan D. Outcomes of pregnancies in women with suspected antiphospholipid syndrome. J Neonatal Perinatal Med 2013;6:225-30.pmid:24246594.

80 Ohkuchi A, Iwasaki R, Suzuki H, et al. Normal and high-normal blood pressures, but not body mass index, are risk factors for the subsequent occurrence of both preeclampsia and gestational hypertension: a retrospective cohort study. Hypertens Res 2006:29:161-7. doi:10.1291/hypres.29.161.

81 Oken E, Ning Y, Rifas-Shiman SL, Rich-Edwards JW, Olsen SF, Gillman MW. Diet during pregnancy and risk of preeclampsia or gestational hypertension. Ann Epidemiol 2007;17:663-8. doi:10.1016/j. annepidem.2007.03.003.
82 Östlund I, Haglund B, Hanson U. Gestational diabetes and preeclampsia. Eur J Obstet Gynecol Reprod Biol 2004;113:12-6. doi:10.1016/j.ejogrb.2003.07.001.

83 Ovesen P, Rasmussen S, Kesmodel U. Effect of prepregnancy materna overweight and obesity on pregnancy outcome. Obstet Gynecol 2011;118:305-12. doi:10.1097/AOG.0b013e3182245d49.

84 Papageorghiou AT, Yu CK, Erasmus IE, Cuckle HS, Nicolaides KH. Assessment of risk for the development of pre-eclampsia by maternal characteristics and uterine artery Doppler. BJOG 2005;112:703-9. doi:10.1111/j.1471-0528.2005.00519.x.

85 Paré E, Parry S, McElrath TF, Pucci D, Newton A, Lim KH. Clinical risk factors for preeclampsia in the 21st century. Obstet Gynecol 2014:124:763-70. doi:10.1097/AOG.0000000000000451.

86 ParkJH, Lee BE, Park HS, Ha EH, Lee SW, Kim YJ. Association between pre-pregnancy body mass index and socioeconomic status and impact on pregnancy outcomes in Korea. J Obstet Gynaecol Res 2011;37:138-45. doi:10.1111/j.1447-0756.2010.01332.x.

87 Persson M, Pasupathy D, Hanson U, Westgren M, Norman M. Pre-pregnancy body mass index and the risk of adverse outcome in type 1 diabetic pregnancies: a population-based cohort study. BM Open 2012;2:e000601. doi:10.1136/bmjopen-2011-000601.

88 Plasencia W, Maiz N, Bonino S, Kaihura C, Nicolaides KH. Uterine artery Doppler at $11+0$ to $13+6$ weeks in the prediction of pre-eclampsia. Ultrasound Obstet Gynecol 2007;30:742-9. doi:10.1002/uog.5157.

89 Plasencia W, Maiz N, Poon L, Yu C, Nicolaides KH. Uterine artery Doppler at $11+0$ to $13+6$ weeks and $21+0$ to $24+6$ weeks in the prediction of pre-eclampsia. Ultrasound Obstet Gynecol 2008;32:138-46. doi:10.1002/uog.5402.

90 Poon LC, Kametas NA, Chelemen T, Leal A, Nicolaides KH. Maternal risk factors for hypertensive disorders in pregnancy: a multivariate approach. J Hum Hypertens 2010;24:104-10. doi:10.1038/ jhh.2009.45.

91 Ramos GA, Caughey AB. The interrelationship between ethnicity and obesity on obstetric outcomes. Am J Obstet Gynecol 2005;193:108993. doi:10.1016/j.ajog.2005.06.040.

92 Rasmussen S. Abruptio placentae - Relationship with other placental dysfunction related conditions. Nor Epidemiol 2007;17:191-7.

93 Rasmussen S, Irgens LM, Albrechtsen S, Dalaker K. Predicting preeclampsia in the second pregnancy from low birth weight in the first pregnancy. Obstet Gyneco 2000;96:696-700.pmid:11042303.

94 Rode L, Nilas L, Wøjdemann K, Tabor A. Obesity-related complications in Danish single cephalic term pregnancies. Obstet Gynecol 2005;105:537-42. doi:10.1097/01.AOG.0000152304.39492.1c.

95 Saereeporncharenkul K. Correlation of BMI to pregnancy outcomes in Thai women delivered in Rajavithi Hospital. J Med Assoc Thai 2011;94(Suppl 2):S52-8.pmid:21717879.

96 Salem Yaniv S, Levy A, Wiznitzer A, Holcberg G, Mazor M, Sheiner E. A significant linear association exists between advanced maternal age and adverse perinatal outcome. Arch Gynecol Obstet 2011;283:755-9. doi:10.1007/s00404-010-1459-4.

97 Salihu HM, Weldeselasse HE, Rao K, Marty PJ, Whiteman VE. The impact of obesity on maternal morbidity and feto-infant outcomes among macrosomic infants. I Matern Fetal Neonatal Med 2011;24:1088-94. doi:10.3109/14767058.2010.546451.

98 Sandvik MK, Iversen BM, Irgens LM, et al. Are adverse pregnancy outcomes risk factors for development of end-stage renal disease in women with diabetes?Nephrol Dial Transplant 2010;25:3600-7. doi:10.1093/ndt/gfq275.

99 Schneider S, Freerksen N, Maul H, Roehrig S, Fischer B, Hoeft B. Risk groups and maternal-neonatal complications of preeclampsia-current results from the national German Perinatal Quality Registry. J Perinat Med 2011;39:257-65. doi:10.1515/jpm.2011.010.

100 Sebire NJ, Jolly M, Harris JP, et al. Maternal obesity and pregnancy outcome: a study of 287,213 pregnancies in London. Int J Obes Relat Metab Disord 2001;25:1175-82. doi:10.1038/sj.ijo.0801670.

101 Shevell T, Malone FD, Vidaver J, et al. Assisted reproductive technology and pregnancy outcome. Obstet Gynecol 2005;106:103945. doi:10.1097/01.AOG.0000183593.24583.7c.

102 Silberstein T, Levy A, Harlev A, Saphier O, Sheiner E. Perinatal outcome of pregnancies following in vitro fertilization and ovulation induction. J Matern Fetal Neonatal Med 2014;27:1316-9. doi:10.3109/14767058.2013.856415.

103 Sohlberg S, Stephansson O, Cnattingius S, Wikström AK. Maternal body mass index, height, and risks of preeclampsia. Am J Hypertens 2012;25:120-5. doi:10.1038/ajh.2011.175.

104 Steinfeld JD, Valentine S, Lerer T, Ingardia CJ, Wax JR, Curry SL. Obesity-related complications of pregnancy vary by race. J Matern Fetal Med 2000;9:238-41 doi:10.1002/1520-6661(200007/08)9:4<238::AIDMFM10>3.0.CO $2-5$.

105 Sun LM, Walker MC, Cao HL, Yang Q, Duan T, Kingdom JC. Assisted reproductive technology and placenta-mediated adverse pregnancy outcomes. Obstet Gynecol 2009;114:818-24. doi:10.1097/ AOG.0b013e3181b76bd1. 
106 Suzuki S, Igarashi M. Risk factors for preeclampsia in Japanese twin pregnancies: comparison with those in singleton pregnancies. Arch Gynecol Obstet 2009;280:389-93. doi:10.1007/s00404-009-0932-4.

107 Tandberg A, Klungsøyr K, Romundstad LB, Skjærven R. Pre-eclampsia and assisted reproductive technologies: consequences of advanced maternal age, interbirth intervals, new partner and smoking habits. BJOG 2015;122:915-22. doi:10.1111/1471-0528.13051.

108 Thomson F, Shanbhag S, Templeton A, Bhattacharya S. Obstetric outcome in women with subfertility. BJOG 2005;112:632-7. doi:10.1111/j.1471-0528.2004.00489.x.

109 Voigt M, Straube S, Zygmunt M, Krafczyk B, Schneider KT, Briese V. Obesity and pregnancy--a risk profile. Z Geburtshilfe Neonatol 2008:212:201-5. doi:10.1055/s-2008-1076995.

110 Wahabi HA, Fayed AA, Alzeidan RA, Mandil AA. The independent effects of maternal obesity and gestational diabetes on the pregnancy outcomes. BMC Endocr Disord 2014:14:47. doi:10.1186/1472-6823-14-47.

111 Walker MC, Murphy KE, Pan S, Yang Q, Wen SW. Adverse maternal outcomes in multifetal pregnancies. BJOG 2004;111:1294-6. doi:10.1111/j.1471-0528.2004.00345.x.

112 Weiss IL, Malone FD, Emig D, et al. FASTER Research Consortium. Obesity, obstetric complications and cesarean delivery rate--a population-based screening study. Am J Obstet Gynecol 2004;190:1091-7. doi:10.1016/j.ajog.2003.09.058.

113 Wright D, Akolekar R, Syngelaki A, Poon LC, Nicolaides KH. A competing risks model in early screening for preeclampsia. Fetal Diagn Ther 2012;32:171-8. doi:10.1159/000338470.

114 Xiong X. Fraser WD, Demianczuk NN. History of abortion, preterm, term birth, and risk of preeclampsia: a population-based study. Am J Obstet Gynecol 2002;187:1013-8. doi:10.1067/mob.2002.126282.

115 Xiong X, Wang FL, Davidge ST, et al. Maternal smoking and preeclampsia. J Reprod Med 2000;45:727-32.pmid:11027081.

116 Yogev Y, Melamed N, Bardin R, Tenenbaum-Gavish K, Ben-Shitrit G Ben-Haroush A. Pregnancy outcome at extremely advanced maternal age. Am J Obstet Gynecol 2010;203:558.e1-7. doi:10.1016/j.ajog.2010.07.039.

117 Zetterström K, Lindeberg SN, Haglund B, Hanson U. Maternal complications in women with chronic hypertension: a populationbased cohort study. Acta Obstet Gynecol Scand 2005;84:419-24. doi:10.1080/j.0001-6349.2005.00508.x

118 Villar JSL, Gulmezoglu AM, Meraldi M, et al. Eclampsia and pre-eclampsia: a health problem for 2000 years. RCOG Press, 2003.

119 Terrin N, Schmid CH, Lau J, Olkin I. Adjusting for publication bias in the presence of heterogeneity. Stat Med 2003;22:2113-26. doi:10.1002/ sim.1461.

120 Sterne JA, Sutton AJ, Ioannidis JP, et al. Recommendations for examining and interpreting funnel plot asymmetry in meta-analyses of randomised controlled trials. BM/ 2011;343:d4002. doi:10.1136/bmj.d4002.

121 Harb HM, Gallos ID, Chu J, Harb M, Coomarasamy A. The effect of endometriosis on in vitro fertilisation outcome: a systematic review and meta-analysis. BJOG 2013;120:1308-20. doi:10.1111/1471-0528.12366.
122 Dwyer T, Couper D, Walter SD. Sources of heterogeneity in the meta-analysis of observational studies: the example of SIDS and sleeping position. / Clin Epidemiol 2001;54:440-7. doi:10.1016/ S0895-4356(00)00313-9.

123 Van Oostwaard MF, Langenveld J, Schuit E, et al. Recurrence of hypertensive disorders of pregnancy: an individual patient data metaanalysis. Am J Obstet Gynecol 2015;212:624.e1-17. doi:10.1016/j. ajog.2015.01.009.

124 Stuart JJ, Bairey Merz CN, Berga SL, et al. Maternal recall of hypertensive disorders in pregnancy: a systematic review. I Womens Health (Larchmt) 2013;22:37-47. doi:10.1089/jwh.2012.3740.

125 Brunelli VB, Prefumo F. Quality of first trimester risk prediction models for pre-eclampsia: a systematic review. BJOG 2015;122:904-14. doi:10.1111/1471-0528.13334

126 Brown CD, Higgins M, Donato KA, et al. Body mass index and the prevalence of hypertension and dyslipidemia. Obes Res 2000;8:60519. doi:10.1038/oby.2000.79.

127 Libby P, Crea F. Clinical implications of inflammation for cardiovascular primary prevention. Eur Heart / 2010;31:777-83. doi:10.1093/ eurheartj/ehq022.

128 Urquia ML, Ray JG. Seven caveats on the use of low birthweight and related indicators in health research. J Epidemiol Community Health 2012;66:971-5. doi:10.1136/jech-2011-200772.

129 Schnohr P, Jensen JS, Scharling H, Nordestgaard BG. Coronary heart disease risk factors ranked by importance for the individual and community. A 21 year follow-up of 12000 men and women from The Copenhagen City Heart Study. Eur Heart / 2002;23:620-6. doi:10.1053/euhj.2001.2842.

130 Schroth WS, Riegelman RK, Blacklow BG. Medical students' risk-taking behavior in "patient" versus "physician" decision frames: implications for medical education. Acad Med 1994;69(Suppl):S54-6. doi:10.1097/00001888-199410000-00041

131 Lee S, Ayers S, Holden D. A metasynthesis of risk perception in women with high risk pregnancies. Midwifery 2014:30:403-11. doi:10.1016/j. midw.2013.04.010.

132 Petersen I, McCrea RL, Lupattelli A, Nordeng H. Women's perception of risks of adverse fetal pregnancy outcomes: a large-scale multinational survey. BMJ Open 2015;5:e007390. doi:10.1136/ bmjopen-2014-007390.

Appendix 1: PubMed and Embase search strategies Appendix 2: Study and participant characteristics for all 92 included cohort studies

Appendix 3: Forest plots

Appendix 4: Funnel plots

Appendix 5: Pooled preeclampsia event rates 